\title{
Anatomia foliar de Richterago Kuntze (Mutisieae, Asteraceae) ${ }^{1}$
}

\author{
Gladys Flávia de A. Melo-de-Pinna²
}

Recebido em 30/03/2001. Aceito em 11/02/2004

\begin{abstract}
RESUMO - (Anatomia foliar de Richterago Kuntze (Mutisieae, Asteraceae)). A estrutura interna da folha de espécies de Richterago mostrou-se bastante variável em relação à organização do mesofilo e à distribuição dos estômatos. Como caráter de valor taxonômico, apenas o tipo de tricoma tector foi utilizado nas relações entre $R$. arenaria e $R$. lanata, $R$. conduplicata e $R$. radiata, cujas folhas são morfologicamente semelhantes. Caracteres relacionados com adaptações ao ambiente xérico, como a ocorrência de extensões da bainha das unidades vasculares e traqueídes terminais, foram encontrados em todas as espécies. Hidatódios foram observados apenas nas duas espécies ribeirinhas ( $R$. polymorpha e $R$. riparia), sendo o primeiro registro de hidatódios em representantes da tribo Mutisieae.
\end{abstract}

Palavras-chave: anatomia foliar, Richterago, Asteraceae

\begin{abstract}
Leaf anatomy of Richterago Kuntze (Mutisieae, Asteraceae)). Leaf anatomy of Richterago species revealed rather variability concerning mesophyll organization and stomata arrangement. As a character of taxonomic value, only non-glandular thricomes were used to compare $R$. arenaria and $R$. lanata, $R$. conduplicata and $R$. radiata, whose leaves are morphologically similar. Anatomical xeromorphic characters, e.g. the bundles sheath extensions and terminal tracheids were observed in all species. The waterside species ( $R$. polymorpha e R. riparia) showed hydathodes in the leaves, which represent the first record in Mutisieae.
\end{abstract}

Kew words: leaf anatomy, Richterago, Asteraceae

\section{Introdução}

A família Asteraceae está bem representada na região semi-árida dos trópicos e subtrópicos (Heywood 1978). A ocupação de representantes dessa família em diferentes nichos ecológicos reflete na plasticidade fenotípica que, na maioria dos casos, se manifesta na estrutura interna dos órgãos vegetativos (Cronquist 1981). No caso da anatomia foliar, vários autores (Carlquist 1957; Felipe \& Alencastro 1966; Handro et al. 1970; Ragonese 1989; Sajo \& Menezes 1994; Luque 1995) têm mencionado a ocorrência de bainha esclerênquimática dos feixes vasculares, mesofilo compacto e estômatos em criptas em diversos representantes da família.

O gênero Richterago Kuntze é endêmico no Brasil e, segundo Roque \& Pirani (2001), está representado por 16 espécies, tendo sido descritas novas espécies com base na morfologia externa. No presente trabalho foram abordados aspectos da anatomia foliar de 11 espécies do gênero Richterago, com o objetivo de corroborar o tratamento taxonômico proposto por Roque \& Pirani (2001).

\section{Material e métodos}

Foram estudadas 11 espécies de Richterago: $R$. stenophylla Cabrera, R. angustifolia (Gardner) Cabrera, $R$. arenaria (Baker) Roque, $R$. radiata (Vell.) Cabrera, $R$. polymorpha (Less.) Cabrera, $R$. conduplicata Roque, R. hatschbachii Zardini, $R$. polyphylla (Baker) Roque, R. riparia Roque, $R$. amplexifolia (Gardner) Roque e $R$. lanata Roque, coletadas na Serra do Cipó, município de Santana do Riacho, MG, Brasil. O material-testemunho encontra-se depositado no Herbário do Departamento de Botânica do Instituto de Biociências da Universidade de São Paulo, SPF (Roque et al. 347, Roque et al. 352, Melo et al. 19, Melo \& Vitta 4, Melo et al. 15, Melo \& Vitta 10, Roque et al. 345, Roque et al. 450, Roque \& Hervêncio 493, Melo \& Vitta 8 e Melo et al. 12).

Ápices caulinares e folhas de cada espécie foram fixados, separadamente, em FAA 50 (Johansen 1940) e, posteriormente, conservados em etanol $70 \%$ (Johansen 1940; Sass 1951). Foram feitos cortes à mão livre do caule na região próxima ao nó e das seguintes regiões da lâmina foliar: base, meio e ápice. Os cortes,

\footnotetext{
1 Parte da Tese de Doutorado da Autora

2 Departamento de Botânica, Universidade de São Paulo, Rua do Matão 277, Cidade Universitária, C. Postal 11461, CEP 05422-970, São Paulo, SP, Brasil (gfmelopinna@ hotmail.com)
} 
após clarificação, foram corados com azul de astra e fucsina básica, seguindo metodologia descrita por Kraus et al. (1998), e montados em bálsamo do Canadá com acetato de butila.

Para determinar o tipo de estômato, utilizou-se a técnica de dissociação da epiderme com peróxido de hidrogênio e ácido acético (Franklin 1945). Os tricomas foram obtidos a partir da raspagem da lâmina foliar e, após clarificação, corados com azul de astra e fucsina básica (Kraus et al. 1998).

Para observação dos hidatódios, as folhas foram diafanizadas em hidróxido de sódio $10 \%$ e, posteriormente, coradas com safranina (Foster 1949). As fotomicrografias foram obtidas em microscópio Olympus-Vanox, e as ilustrações, ao microscópio de luz com emprego de câmara-clara.

\section{Resultados}

As folhas de quase todas as espécies são subsésseis, exceto em $R$. riparia, $R$. amplexifolia e $R$. hatschbachii, que são pecioladas. Nessas espécies observa-se que o pecíolo, em secção transversal, apresenta forma plano-convexa (Fig. 1 e 3 ) ou côncavo-convexa (Fig. 2). A epiderme, no pecíolo, é unisseriada, e as paredes de suas células podem ser delgadas, como em R. hatschbachii (Fig. 4) ou apresentar espessamento apenas na parede periclinal externa, como em $R$. riparia (Fig. 5) e $R$. amplexifolia. Dessas três espécies, as células epidérmicas de $R$. hatschbachii estão revestidas por uma cutícula, na qual se observam distintas regiões do estrato cuticular (Fig. 4): uma região próxima ao

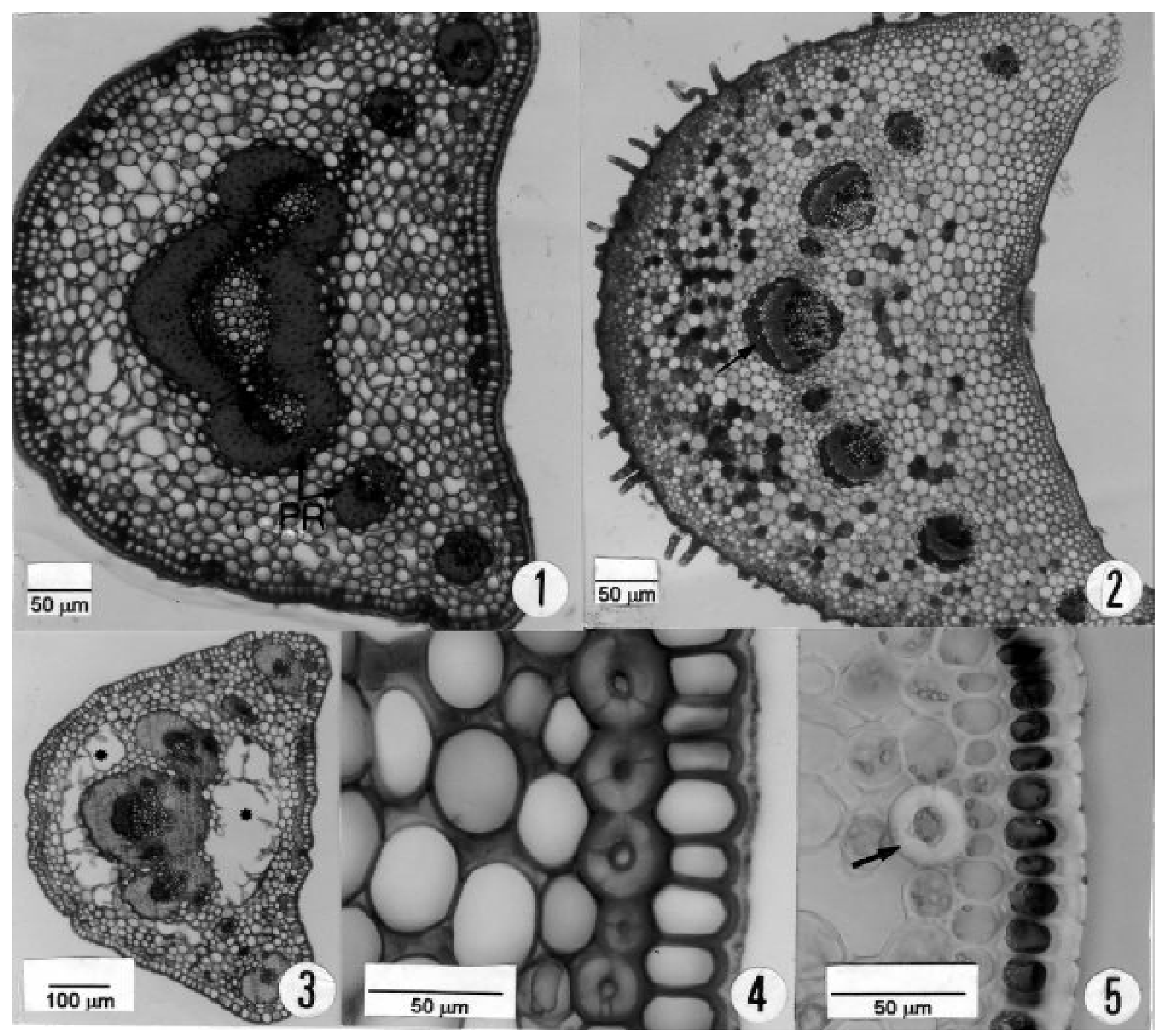

Figuras 1-5. Secções transversais do pecíolo de espécies de Richterago. 1. Richterago riparia, onde se observam fibras pericíclicas (PR) envolvendo as unidades vasculares (setas). 2. R. amplexifolia, evidenciando o periciclo constituído de fibras (seta). 3. Richterago hatschbachii, com aerênquima na região cortical (*). 4-5. Detalhes da região externa do córtex, destacando a ocorrência de esclereídes abaixo da epiderme e na camada subseqüente (seta) de Richterago hatschbachii e Richterago amplexifolia, respectivamente. 
citoplasma da célula, que corresponde, possivelmente, à parede celulósica; uma região intermediária e uma mais externa, que representa a cutícula propriamente dita.

No pecíolo, as unidades vasculares encontram-se agrupadas em forma de "meia-lua" (Fig. 1-3), variando em número de cinco a nove e, no caso de $R$. hatschbachii apresentam-se, praticamente, envolvidas por aerênquima (Fig. 3). Observa-se uma disposição colateral dos tecidos vasculares e a presença de fibras pericíclicas envolvendo esses tecidos (Fig. 1-3).

Em secções transversais da lâmina foliar de cada espécie estudada verificou-se que em $R$. polymorpha
(Fig. 6), R. amplexifolia (Fig. 7), R. polyphylla, $R$. riparia, $R$. arenaria, $R$. conduplicata, $R$. lanata, $R$. hatschabchii e $R$. radiata é possível distinguir a região correspondente à unidade vascular central. Já em $R$. stenophylla (Fig. 8) e R. angustifolia (Fig. 9) as unidades vasculares não se diferenciam entre si.

Nas espécies estudadas, o mesofilo pode ser homogêneo, como em R. stenophylla (Fig. 8), $R$. angustifolia (Fig. 9), $R$. riparia (Fig. 10) e alguns indivíduos de $R$. conduplicata (Fig. 12, 14); isobilateral, como em $R$. arenaria (Fig. 11) ou dorsiventral, como em $R$. amplexifolia (Fig. 13). Quando o mesofilo é do tipo isobilateral ou dorsiventral, o parênquima lacunoso está representado por células braciformes, cujas projeções podem ser discretas ou bastante acentuadas,

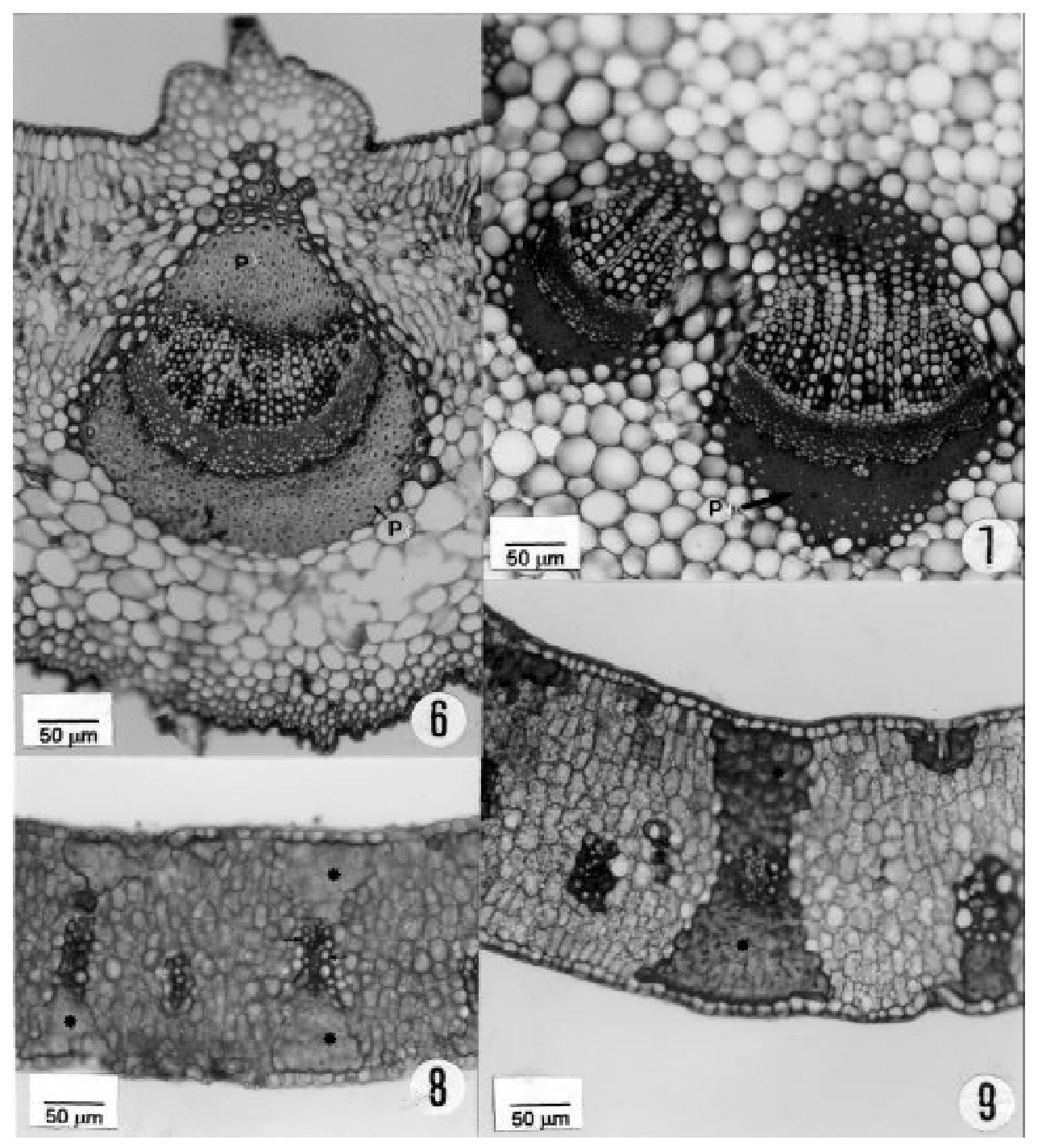

Figuras 6-9. Secções transversais da lâmina foliar de espécies de Richterago. 6-7. Detalhes das unidades vasculares medianas em Richterago amplexifolia e Richterago polyphylla, evidenciando o periciclo (P) constituído de fibras. 8-9. Richterago stenophylla e Richterago angustifolia: notar disposição das unidades vasculares e as extensões de bainha integradas por fibras (*). 


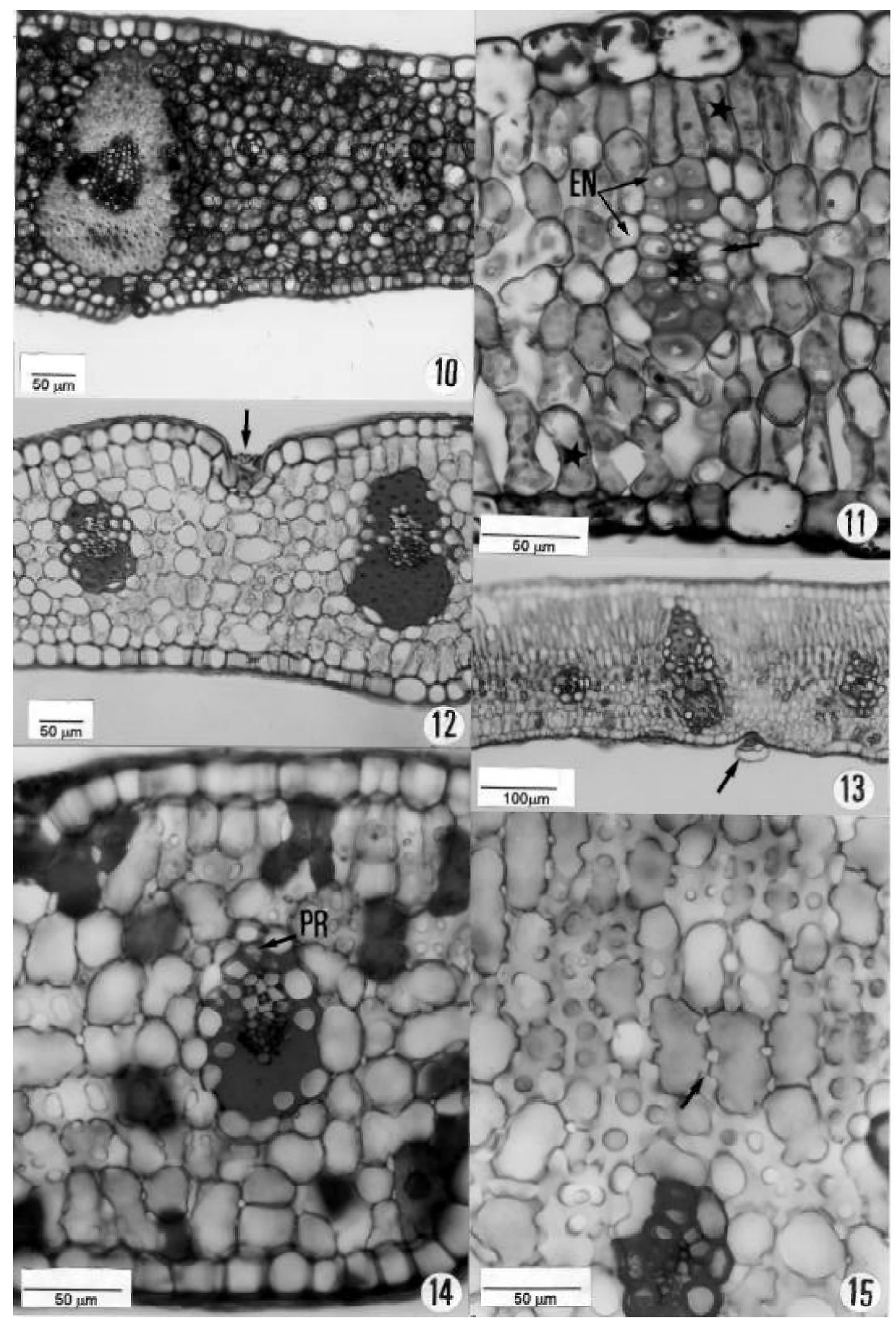

Figuras 10-15. Secções transversais da lâmina foliar de espécies de Richterago. 10. Richterago riparia: mesofilo homogêneo e as unidades vasculares situada na região mediana. 11. Richterago arenaria: mesofilo isobilateral (*). 12. Richterago conduplicata: mesofilo isobilateral pouco diferenciado. Notar presença de tricoma glandular (seta) em depressão. 13. Richterago amplexifolia: mesofilo bilateral. Notar presença de tricoma glandular (seta). 14. Richterago lanata: mesofilo homogêneo. 15. Richterago amplexifolia: células braciformes com projeções (seta). $\mathrm{EN}=$ endoderme; $\mathrm{PR}=$ periciclo. 
como em $R$. amplexifolia (Fig. 15). Em relação ao parênquima paliçádico, não há expressiva diferenciação das células, exceto em $R$. amplexifolia (Fig. 13) e $R$. arenaria (Fig. 11). Nesta última espécie, em uma população sob mesmas condições climáticas (exposta ao sol), observou-se variação na organização do mesofilo, tendo alguns indivíduos esse tecido pouco diferenciado em paliçádico e lacunoso, e outros indivíduos em que o mesofilo é fortemente bilateral, com duas a três camadas de paliçádico na superfície adaxial.

As unidades vasculares encontram-se dispostas na posição mediana do mesofilo (Fig. 9-14). Cada unidade é envolvida por uma bainha de fibras que pode ser constituída de fibras pericíclica e endodérmica (Fig. 11, 14). Nas espécies $R$. stenophylla (Fig. 8, 17) e R. angustifolia (Fig. 9) a bainha de fibras também é constituída de células do mesofilo que se lignificaram, formando as extensões da bainha. A lignificação das células do mesofilo pode iniciar em direção às duas superfícies ou apenas para uma.

$\mathrm{Na}$ lâmina foliar, as células epidérmicas são revestidas por cutícula espessada, em algumas espécies, como em $R$. amplexifolia (Fig. 16) ou fortemente espessada, como em $R$. hatschbachii (Fig. 18). As células epidérmicas podem apresentar diferença no tamanho, sendo as da superfície adaxial maiores que as da abaxial, como em $R$. amplexifolia

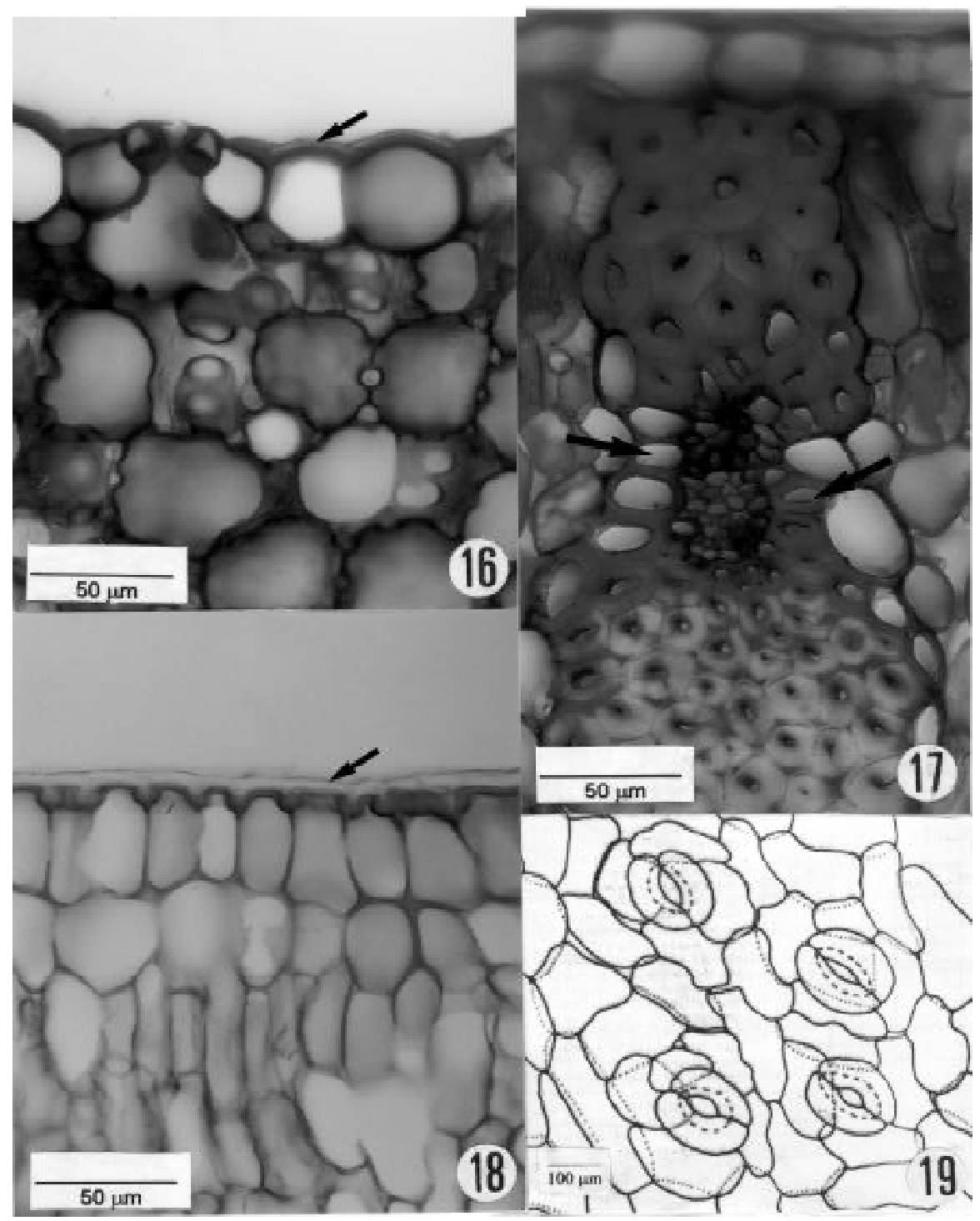

Figuras 16-19. Secções transversais da lâmina foliar de espécies de Richterago. 16. Richterago hatschbachii: detalhe da região superior do mesofilo, mostrando células braciformes e cutícula (seta) revestindo a epiderme. 17. Richterago angustifolia: detalhe de uma unidade vascular. Notar células pericíclicas lignificadas (setas). 18. Richterago amplexifolia: cutícula revestindo epiderme (seta). 19. Representação esquemática da epiderme dissociada da folha de Richterago conduplicata, evidenciando os estômatos anomocíticos. 
(Fig. 13) e $R$. arenaria (Fig. 11), ou ter o mesmo tamanho, como em $R$. conduplicata (Fig. 14) e $R$. riparia (Fig. 10).

Apenas um tipo de estômato anomocítico foi observado nas espécies estudadas, sem diferenciação entre as células subsidiárias e as demais células epidérmicas (Fig. 19). A ocorrência dos estômatos é bastante variável, podendo-se encontrar, em um mesmo indivíduo, folhas anfiestomáticas ou hipoestomáticas, como em $R$. radiata. No entanto, observa-se que há maior ocorrência de folhas anfiestomáticas.

Tricomas glandulares e tectores foram observados na maioria das espécies estudadas. Tricoma glandular capitado com base bisseriada foi registrado para quase todas as espécies, como o que se vê, por exemplo, em R. radiata (Fig. 20). Os tricomas glandulares ocorrem nas duas superfícies epidérmicas e, quando presentes na região da nervura central, localizam-se ao nível das demais células epidérmicas. No entanto, na região da lâmina foliar estes tricomas, freqüentemente, estão situados em depressões (Fig. 12 e 13).

Os tricomas tectores, na sua maioria, são revestidos nas células basais pela cutícula, como ocorre em R. polyphylla (Fig. 21). Os tricomas são bastante variáveis e, na maioria das espécies, ocorrem em grande número. As Fig. 22 a 28 mostram os principais tipos de tricomas tectores encontrados nas diferentes espécies. Observa-se que todos os tricomas são multicelulares, variando a forma das células. As paredes terminais podem ser fortemente oblíquas, como por exemplo no tipo de tricoma de $R$. conduplicata (Fig. 23), ou levemente oblíquas, como

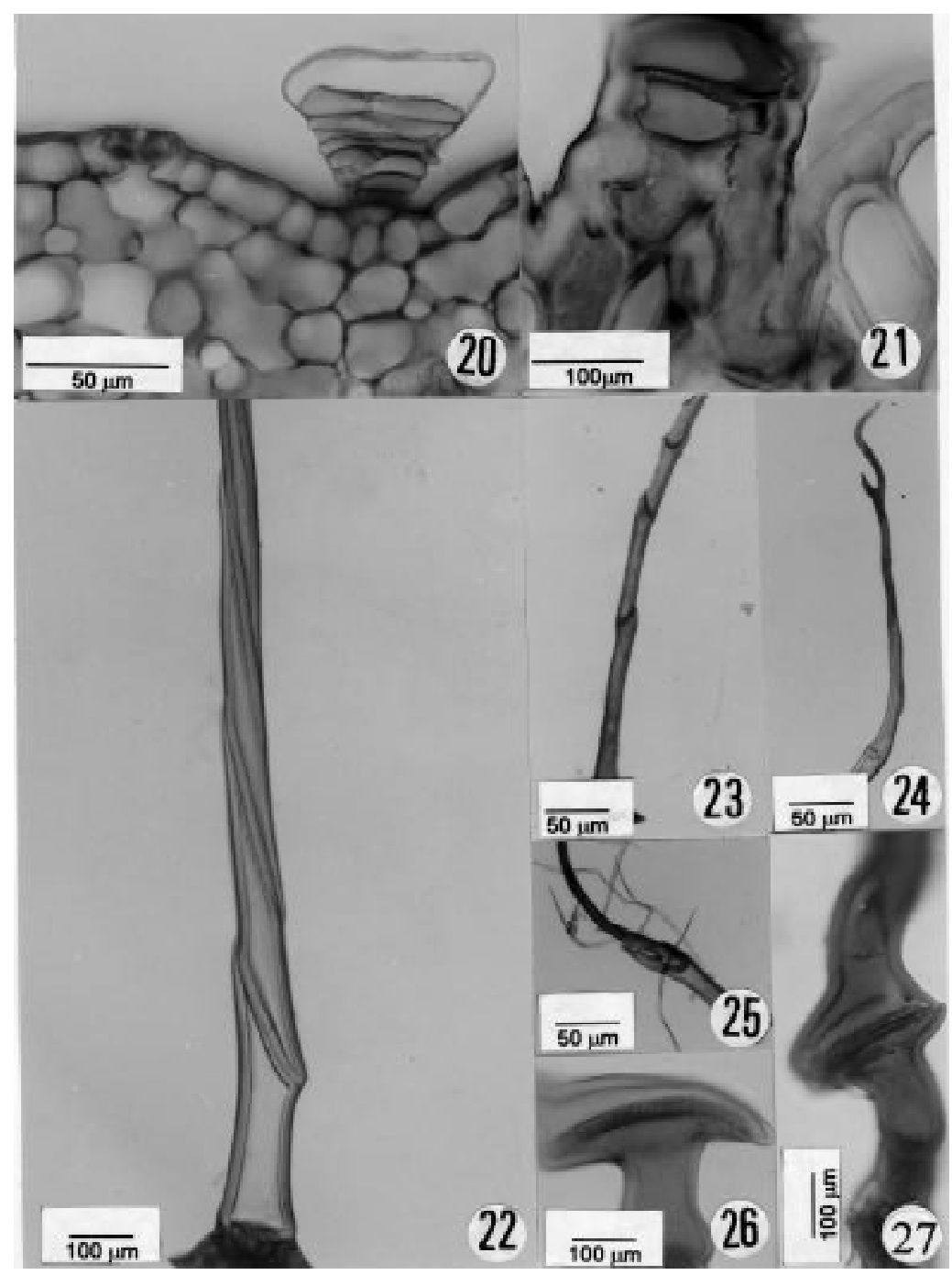

Figuras 20-27. Diferentes tipos de tricomas encontrados nas folhas de espécies de Richterago. 20. Tricoma glandular, multicelular com a distensão da cutícula na extremidade superior. 21. Base de um tricoma tector de Richterago polyphylla. Notar a presença de uma cutícula espessa revestindo a epiderme e as células basais do tricoma. 22-27. Variações dos tricomas tectores presentes em Richterago lanata (22), Richterago conduplicata (23), Richterago radiata (24-25), Richterago polyphylla (26) e Richterago amplexifolia (27). 
ocorre na maioria das espécies, como por exemplo em $R$. lanata (Fig. 22). Apenas em $R$. radiata observou-se tricomas com uma projeção lateral da parede terminal de uma das células. Essa projeção pode estar situada próxima ao ápice (Fig. 24), ou próxima à base (Fig. 25). Outra variação na forma das células foi observada em $R$. polyphylla (Fig. 26). Nesta espécie, foram observados tricomas nos quais uma das células, próxima à base, apresenta forma de "martelo", como pode ser visto em detalhe da Fig. 26. Tricoma semelhante ao descrito foi observado em R. amplexifolia (Fig. 27), onde há um achatamento das paredes terminais de duas células em contato. Em $R$. radiata (Fig. 28), foram observados tricomas apresentando duas células basais.

Característica observada em todas as espécies foi a presença de traqueídes terminais (Fig. 29) com espessamento helicoidal, envolvidas pela endoderme. Em $R$. polymorpha e $R$. riparia, foram observados hidatódios que podem ocorrer nas regiões correspondentes aos dentes marginais da folha (Fig. 30), e no ápice (Fig. 31). O número de hidatódios marginais aumenta conforme a idade da folha, variando de dois a 20. A Fig. 30 mostra uma secção paradérmica da região correspondente a um dente, em que se verifica um conjunto de traqueídes que são circundadas pelo epitema e um poro, representado por um estômato não funcional.

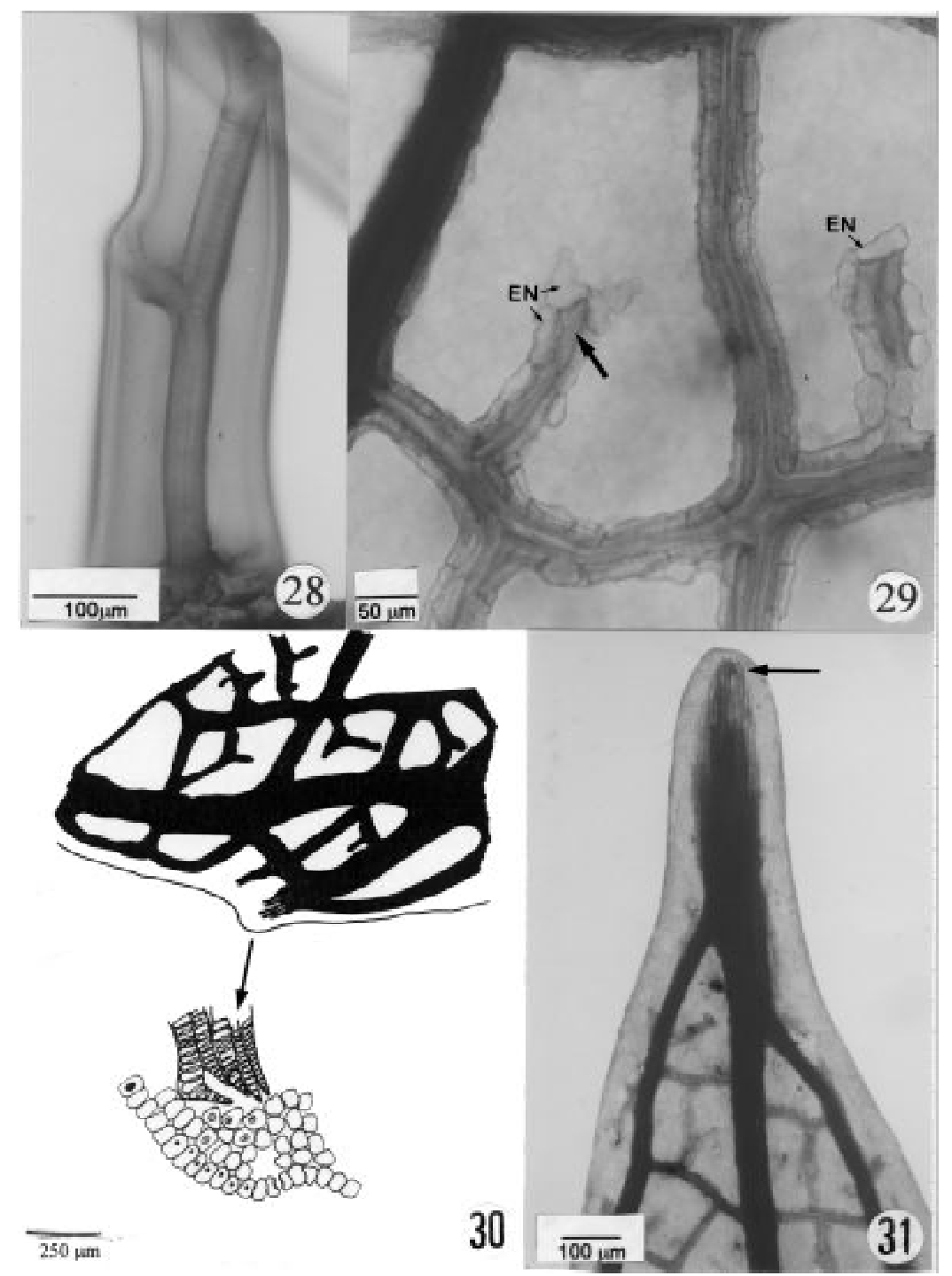

Figuras 28-31. Tricoma tector, traqueídes terminais e hidatódio em folhas de espécies de Richterago. 28. Pormenor da região basal do tricoma tector encontrado apenas em Richterago radiata. 29. Folha diafanizada de Richterago riparia, mostrando as traqueídes terminais (seta maior) revestidas pela endoderme (EN). 30. Representação esquemática do bordo foliar de Richterago polymorpha, na região correspondente a um dente (seta). 31. Ápice da folha de Richterago riparia, mostrando hidatódio terminal (seta). 


\section{Discussão}

A anatomia foliar de representantes de Asteraceae vem sendo utilizada por alguns autores na caracterização de tribos e alguns gêneros (Carlquist 1959a; 1959b; Felipe \& Alencastro 1966; Anderson \& Creech 1975; Breitwieser 1993). Após a revisão feita por Roque \& Pirani (2001), o gênero Richterago passou a ser representado por 16 espécies endêmicas do Brasil, devido à transferência de $R$. corymbosa, que ocorre em outros países da América do Sul, para o gênero Ianthopappus (Roque \& Hind 2001).

Dos resultados obtidos neste trabalho, o único caráter que se manteve constante nos indivíduos analisados e que pode ser utilizado na diagnose de algumas espécies foi o tipo de tricoma. Este caráter pode ser utilizado na determinação dos seguintes conjuntos de espécies: $R$. lanata - $R$. arenaria e $R$. conduplicata $-R$. radiata, que apresentam grandes similaridades morfológicas entre si, sendo $R$. lanata e $R$. conduplicata duas novas espécies propostas por Roque \& Pirani (2001). R. arenaria apresenta tricomas com ápice bífido e tricomas com projeções laterais de algumas células, que não ocorrem em $R$. lanata. Já em $R$. radiata, foram observados tricomas com duas séries de células, na região basal, ausentes em $R$. conduplicata.

Uma segunda situação em que dados anatômicos podem auxiliar a taxonomia é o referente a $R$. amplexifolia. Esta espécie, anteriormente descrita para o gênero Gochnatia, apresenta os mesmos tipos de tricomas encontrados nas demais espécies de Richterago, corroborando, desta forma, a transferência genérica conforme proposto por Roque (2001).

Outro aspecto também utilizado como subsídio taxonômico, é a organização do mesofilo (Breitwieser 1993; Breitwieser \& Ward 1998). Em Richterago, este carater apresentou variações intraespecíficas, portanto não poderia ser utilizado na delimitação das espécies, nem na caracterização do gênero. Variação na organização do mesofilo também foi observada por diversos autores, como Anderson \& Creech (1975), estudando 63 espécies de Asteraceae; Breitwieser (1993), para as espécies da tribo Inuleae da Nova Zelândia e Tasmânia; e Breiwieser \& Ward (1998), com espécies de Raoulia. Contudo, esta variação não foi observada intraespecificamente, como em Richterago, uma vez que esses autores utilizaram a organização do mesofilo na delimitação dos táxons. Por outro lado, Luque (1995), estudando
36 espécies de Lychnophora de campo rupestre, descreveu para todas as espécies mesofilo do tipo dorsiventral.

Quanto à distribuição dos estômatos, Breitwieser (1993) observou que, em espécies da tribo Inuleae com mesofilo dorsiventral, os estômatos ocorrem, freqüentemente, na superfície abaxial e, nas espécies com mesofilo dorsiventral-inverso, os estômatos estão na superfície adaxial. No entanto, o autor mencionou que há algumas exceções, como Pseudognaphalium luteoalbum que apresenta mesofilo dorsiventral e tem estômatos em ambas as superfícies. Em Richterago, em que a maioria das folhas é anfiestomática, devido à variação observada na distribuição dos estômatos intraespecificamente, não foi possível observar qualquer relação deste caráter com a organização do mesofilo.

Além de não subsidiar a taxonomia, caracteres como a organização do mesofilo e a distribuição dos estômatos na epiderme não deveriam ser utilizados como de valor adaptativo para as espécies de Richterago, uma vez que, em uma mesma população, indivíduos apresentam diferentes padrões na organização do mesofilo e, principalmente, na distribuição dos estômatos.

Breitwieser (1993) e Breitwieser \& Ward (1998) relacionaram a organização do mesofilo e o tamanho das células epidérmicas nas duas superfícies como caracteres diagnósticos para espécies de Asteraceae. Breitwieser (1993), estudando espécies da tribo Inuleae, mencionou que nas espécies com mesofilo dorsiventral, as células epidérmicas da superfície adjacente ao paliçádico são maiores que as da outra superfície. $\mathrm{O}$ autor mencionou ainda que esta relação não é regra geral, tendo sido encontrados casos intermediários e mesmo a ausência dessa diferença. Em Richterago, algumas espécies, como por exemplo $R$. arenaria e $R$. conduplicata, apresentam mesofilo isobilateral; no entanto, em $R$. arenaria as células da superfície adaxial são maiores que a da abaxial e em $R$. conduplicata, as células das duas superfícies são de igual tamanho. Apenas $R$. amplexifolia parece demonstrar esta relação, pois o mesofilo é fortemente dorsiventral e as células da superfície adaxial são maiores que as da abaxial.

Para a família Asteraceae, alguns caracteres parecem ser freqüentes, como por exemplo a presença de fibras ao redor das unidades vasculares, referidas por Carlquist (1957), Anderson \& Creech (1975) e Breitwieser (1993) como feixes vasculares. Neste trabalho está sendo adotado o termo unidade vascular, conforme proposto por Menezes et al. 
(2003). Todas as espécies de Richterago estudadas apresentaram bainha de fibras, que pode ser constituída unicamente de fibras pericíclicas, ou também por células lignificadas da endoderme. Nos casos onde há extensões da bainha, como em $R$. stenophylla, $R$. angustifolia e $R$. amplexifolia, além das fibras pericíclicas e endodérmicas, algumas células do mesofilo se lignificam. A ocorrência de extensões da bainha nas unidades vasculares referidas para diferentes gêneros de Asteraceae, é, segundo Fahn \& Cutler (1992), uma das características adaptativas encontradas nas xerófitas, por serem as fibras condutoras de água.

Em quase todas as espécies, a endoderme na folha adulta fica completamente espessada. No entanto, é possível diferenciar de uma fibra pericíclica pelo diâmetro do lúmen da célula (muito reduzido na fibra pericíclica).

Em relação à presença de hidatódios, apenas as espécies $R$. polymorpha e $R$. riparia apresentaram esta estrutura. É importante salientar que essas duas espécies são as únicas ribeirinhas, ocorrendo em solo encharcado ( $R$. polymorpha) ou sob pedras imersas na lâmina d'água ( $R$. riparia), onde possivelmente essas estruturas estariam relacionadas ao controle interno de água nas plantas que, por ocuparem preferencialmente ambientes secos, não estariam adaptadas à grande disponibilidade de água. Esta consideração baseia-se no fato de terem sido observados indivíduos sem hidatódios das duas espécies em solo não encharcado.

Autores como Solereder (1908) e Metcalfe \& Chalk $(1950 ; 1979)$ consideraram rara a ocorrência de hidatódios na família Asteraceae. Em levantamento sobre a distribuição e anatomia de hidatódios em Asteraceae, desenvolvido por Lersten \& Curtis (1985), os autores relataram que esta estrutura ocorre em 80 gêneros pertencentes a 10 tribos, o que contribuiu de forma marcante para os estudos sobre hidatódios na família. Nesse trabalho, não foi citada a tribo Mutisieae e, de acordo com o levantamento realizado pelos autores do presente trabalho, o primeiro registro de hidatódios na tribo Mutisieae resume-se a este estudo com Richterago.

\section{Agradecimentos}

À Coordenação de Aperfeiçoamento Pessoal de Ensino Superior (CAPES-PICDT/UFPE), pelo auxílio financeiro.

\section{Referências bibliográficas}

Anderson, L.C. \& Creech, J.B. 1975. Comparative leaf anatomy of Solidago and related Asteraceae. American Journal of Botany 62(5): 486-493.

Breitwieser, I. 1993. Comparative leaf anatomy of New Zealand and Tasmanian Onuleae (Compositae). Botanical Journal of the Linnean Society 111: 183-209.

Breitwieser, I. \& Ward, J.M. 1998. Leaf anatomy of Raoulia Hook. f. (Compositae, Gnaphalieae). Botanical Journal of the Linnean Society 126: 217-235.

Carlquist, S. 1957. Leaf anatomy and ontogeny in Argyroxiphium and Wilkesia (Compositae). American Journal of Botany 44: 696-705.

Carlquist, S. 1959a. The leaf of Calycadenia and its glandular appendages. American Journal of Botany 46: 70-80.

Carlquist, S. 1959b. Glandular structure of Holocarpha and their ontogeny. American Journal of Botany 46: 300-308.

Cronquist, A. 1981. An integrated system of classification of flowering plants. Columbia, University Press, New York.

Fahn, A. \& Cutler, D.F. 1992. Xerophytes. Gebrüder Borntraeger, Encyclopedia of plant anatomy, Berlin.

Felippe, G.M. \& Alencastro, F.M.M.R. 1966. Contribuição ao estudo da nervação foliar das Compositae dos Cerrados: I - Tribus Helenieae, Heliantheae, Inuleae, Mutisieae e Senecionae. Anais da Academia Brasileira de Ciência 38: 125-156.

Foster, A.S. 1949. Pratical plant anatomy. D. van Nostrand Company. Princeton.

Franklin, G.L. 1945. Preparation of thin sections of synthetic resins and wood-resin composites, and a new macerating method for wood. Nature 155(3924): 51.

Handro, W.; Campos, J.F.B.M. \& Oliveira, Z.M. 1970. Sobre a anatomia foliar de algumas compostas dos campos rupestres. Ciência e Cultura 22(2): 107-127.

Heywood, V.H. 1978. Flowering plants of the world. Oxford University Press, Oxford.

Johansen, D.A. 1940. Plant microtechnique. McGraw-Hill, New York.

Kraus, J.E.; Sousa, H.C.; Rezende, M.H.; Castro, N.M.; Vecchi, C. \& Luque, R. 1998. Astra blue and basic fucsin double staining of plant materials. Biotechnic \& Histochemistry 73(5): 235-243.

Lersten, N.R. \& Curtis, J.D. 1985. Distribution and anatomy of hydathodes in Asteraceae. Botanical Gazette 146(1): 106-114.

Luque, R. 1995. Estudo morfoanatômico em espécies de Lychnophora Mart. (Asteraceae) dos campos rupestres do Brasil. Tese de Doutorado, Instituto de Biociências, Universidade de São Paulo.

Menezes, N.L.; Silva, D.C. \& Melo-de-Pinna, G.F.A. 2003. Folha. Pp. 301-325. In: B. Appezzato-da-Glória \& S.M. Carmello-Guerreiro (eds.). Anatomia Vegetal. Editora UFV, Viçosa.

Metcalfe, C.R. \& Chalk, L. 1950. Anatomy of the dicotyledons. v.2. Claredon Press, Oxford.

Metcalfe, C.R. \& Chalk, L. 1979. Anatomy of the dicotyledons. $2^{\text {nd }}$ ed. v.1. Claredon Press, Oxford. 
Ragonese, A.M. 1989. Criptas estomáticas foliares em Eupatorium bupleurifolium (Compositae). Darwiniana 29(1-4): 9-15.

Roque, N. 2001. Generic delimitation of Gochnatia Kunth, Richterago Kuntze and Ianthopappus Roque \& D.J.N Hind (Compositae, Mutisieae) based on pollen morphology. Grana Palynologica 40(4-5): 197-204.

Roque, N. \& Pirani, J.R. 2001. Reinstatement of the name Richterago Kuntze and recircumscription of the genus to include species formerly treated as Actinoseris (Less.) Cabrera (Compositae, Mutisieae). Taxon 50: 1155-1160.

Roque, N. \& Hind, D.J.N. 2001. Ianthopappus a new genus of the tribe Mutisieae (Compositae). Novon 11: 96-100.
Roth, I. 1973. Anatomia de las hojas da plantas de los Paramos Venezolanos. 2: Espeletia (Compositae). Acta Botanica Venezolana 8: 281-310.

Sajo, M.G. \& Menezes, N.L. 1994. Considerações sobre anatomia foliar de espécies de Vernonia Screb. (Compositae) da Serra do Cipó, MG. Naturalia 19: 173-183.

Sass, J.E. 1951. Botanical microtechnique. Iowa State College Press, Ames.

Solereder, H. 1908. Systematic anatomy of the dicotyledons. Trans. L.A. Boodle \& F.E. Fritsch. Oxford University Press, Oxford. 